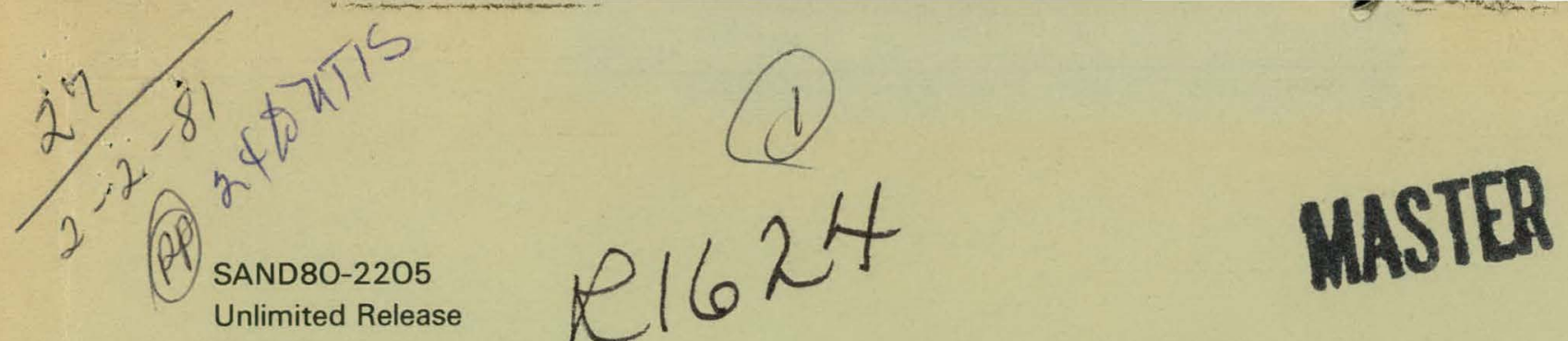

\title{
Megaflop Comparisons of Various Computers
}

Thomas H. Jefferson, Melvin R. Scott

Prepared by Sandia National Laboratories. Albuquerque. New Mexico 87185

and Livermore, California $9455 \mathrm{n}$ for the IInited States Department

of Energy under Contract DE-ACO4-76DPO0789

Printed October 1980 


\section{DISCLAIMER}

This report was prepared as an account of work sponsored by an agency of the United States Government. Neither the United States Government nor any agency Thereof, nor any of their employees, makes any warranty, express or implied, or assumes any legal liability or responsibility for the accuracy, completeness, or usefulness of any information, apparatus, product, or process disclosed, or represents that its use would not infringe privately owned rights. Reference herein to any specific commercial product, process, or service by trade name, trademark, manufacturer, or otherwise does not necessarily constitute or imply its endorsement, recommendation, or favoring by the United States Government or any agency thereof. The views and opinions of authors expressed herein do not necessarily state or reflect those of the United States Government or any agency thereof. 


\section{DISCLAIMER}

Portions of this document may be illegible in electronic image products. Images are produced from the best available original document. 
Issued by Sandia National Laboratories, operated for the United States Department of Energy by Sandia Corporation

\section{NOTICE}

This report was prepared as an account of work sponsored by the United States Government. Neither the United States nor the Department of Energy, nor any of their employees, nor any of their contractors, subcontractors, or their employees, makes any warranty, express or implied, or assumes any legal liability or responsibility for the accuracy, completeness, or usefulness of any information, apparatus, product or process disclosed, or represents that its use would not infringe privately owned rights.

Printed in the United States of America

Available from

National Technical Information Service

II.S. Department of Commerce

5285 Port Royal Road

Springfield, VA 22161

Price: Printed Copy $\$ 4.00 ;$ Microfiche $\$ 3$ 


\section{PAGES 1 to 2 WERE INTENTIONALLY LEFT BLANK}


SAND 80-2205

Unlimited Release

Printed October 1980

Megaflop Comparisons of Various Computers

Thomas H. Jefferson

Applied Mathematics Division, 8332

Sandia National Laboratories

Livermore, California 94550

and

Melvin R. Scott

Applied Mathematics Division, 2646

Sandia National Laboratories

Albuquerque, New Mexico 87185

\section{Abstract}

This report describes a test program and results obtained by running this program on a wide range of computers of interest to sandia National Laboratories. The program, written in FORTRAN, was designed to estimate the speed with which a target computer could perform floating point operations requested by a FORTRAN programmer. Input/. output operations are not timed. Thus the results depend not only upon the basic underlying speed of the computer but also upon the intelligence of the FORTRAN compiler. 


\section{Introduction}

Performance testing of a computer is, at best, an inexact science. Any test that can be devised is still only an isolated test, and any general conclusions based on that test should be carefully scrutinized. It would, of course, be desirable to have a set of programs which exactly model the workload for a particular installation. However, it is impossible to build such a model. Even if it could be done, extrapolating the results to other work loads would be risky. In general, the more realistic the set of benchmark programs, the more machine-dependent they become. This is particularly true if time-sharing exercises are involved. Nevertheless, it is desirable to have a test or tests which are portable and can be used as a basis for simple comparisons of various computers.

This report describes a test program and results obtained by running this program on a wide range of computers of interest to sandia National Laboratories. The program, written in FORTRAN, was designed to estimate the speed with which a target computer could perform Eloating point operations requested by a FORTRAN programmer. Input/ output operations are not timed. Thus the results depend not only upon the basic underlying speed of the computer but also upon the intelligence of the FORTRAN compiler. It is entirely possible that an optimizing compiler might generate code with fewer floating point operations than generated by a nonoptimizing compiler.

However, in examining the code generated by the FTN compiler on Control Data equipment, we found that the number of floating point operations was not changed by varying the optimization parameter. Thus when changes occur in the timings by changing the optimization parameters, we are seeing the ability of the compiler to optimize the overhead associated with indexing of Do loops, IF tests, jumps, etc. Unfortunately, it is almost impossible to separate the time associated with floating point calculations from other activities.

\section{Description of Test Program}

The program, SPEED, is written in ANSI (1966) standard FORTRAN so that only one or two lines need be changed to run on any of the machines. Some computers require a PROGRAM card as the initial card, and the call to the internal clock might have to be changed. A microfiche copy of SPEED is attached to the back cover of this reporl.

SPEED consists of Eive sections or kernels which are described briefly as follows:

Kerne I

Description

Linear Equation Solver without Pivoting. Gaussian elimination without pivoting is used to solve systems of sizes $1,2, \ldots$. The 
2

3

4

5 maximum-sized system solved is an input variable set to 60 for these tests.

Excerpt From Ordinary Differential Equation Solver. This kernel is part of the prediction step of an ODE solver, the major computation being done in a short Do loop with two additions and a multiplication.

Forward and Backward Substitution Excerpt From Linear Equation Solver with Pivoting. The test results are obtained with 29 iterations of Forward/Backward substitution for linear systems of sizes 50 through 100 .

Excerpt From Vortex Dynamics Code. The major computational loop in this kernel is a 17-statement inner DO loop containing branching and an external reference to the square root routine.

Excerpt From Lattice Relaxation Code. This rather complicated kernel contains several. inner DO loops of varying complexity, including branching and exponentiation.

These kernels were all taken from programs in use at sandia in 1978. The first three were adapted from software library routines while the fourth and fifth were taken from large user codes. Each kernel was modified only enough so that it would run to completion with varying input parameters without encountering arithmetic difficulties.

The number of millions of floating point operations* per second (MFLOPS) for each kernel is computed separately. Then the overall total MFLOPS is calculated by dividing the total number of millions of floating point operations for all kernels by the total time for all kernels.

The number of floating point operations performed by the program with varying inputs was arrived at by judging what economizing operations a reasonable compiler would do. It is recognized that on certain computers, changing a few lines of code could give rise to greatly different results. Thus the results of running the program unmodified must not be interpreted as the speed at which the same work ciuld be done if the kernels were rewritten to account for the machine's architecture.

*A floating point operation is defined to be an add, subtract, multiply, or divide with each operation counting equally. 
Test Results

These tests have been performed at various sites over the past 12 months. We shall identify the results as carefully as possible because it is doubtful that any of the tests could be duplicated, especially if there have been changes to the operating systems which were used.

Each test was run with the compiler and optimization parameters to give the fastest possible results. All results were obtained by running the program in single precision. Thus, for examples, results were obtained on the VAX using 32 bits and on the CDC-203 and CRAY-l using 64 bits.

\section{Conclusions}

We have used a specially prepared FORTRAN program, SPEED, to measure the central processor capability of several computers. The program calculates the number of miliions of floating point operations per second for five kernels originally written for a CDC-6600.

While it is true that the performance of any particular machine could be enhanced by tailoring the code to the architecture of that machine, we have chosen to run the code unmodified across all machines. A future report will discuss methods of improving the performance by taking advantage of. the architecture.

MS : pm1 : 4914A: 01/05/81 


\begin{tabular}{|c|c|c|c|c|c|c|}
\hline Compister & Losation & . & Operating system & Compiler & $\begin{array}{c}\text { Word } \\
\text { Length } \\
\text { (Bits) } \\
\end{array}$ & Date \\
\hline $\operatorname{VAx} 11 / 780$ & Sandia & & VMS 1.6 & FORTRAN IV-PLUS & 32 & $6 / 10 / 80$ \\
\hline UNIVAC $1: 08$ & Sandia & & EXEC-Vlll-Level 31 & FORTRAN V & 36 & $4 / 05 / 80$ \\
\hline UNIVAC $1100 / 82$ & Sandia & & EXEC-Vlll-Level 36 & FTN & 36 & $4 / 05 / 80$ \\
\hline CDC- 6400 & Sand $i a$ & & NOS/BE 1.2 & FTN $4.6+460$ & 60 & $3 / 31 / 80$ \\
\hline CDC-CYBEF: 172 & Sandia & & SCOPE 3.3 & FTN & 60 & $4 / 05 / 80$ \\
\hline CDC- 6600 & Sandia & & NOS & FTN & 60 & $4 / 05 / 80$ \\
\hline $\mathrm{CDC}-7600$ & Sandia & & SCOPE 2.1 & FTN $4.6+452$ & 60 & $1 / 04 / 79$ \\
\hline I BM-3033 & BENDIX-KC & & MV370-CMS & Level $\mathrm{H}--$ Ex tended & 32 & $11 / 15 / 79$ \\
\hline CYBER $170 / 720$ & CDC-MINN & & NOS -485 & FORTRAN 5 & 60 & $4 / 30 / 80$ \\
\hline CYBER $170 / 730$ & CDC-MINN & & NOS -485 & FORTRAN 5. & 60 & $4 / 30 / 80$ \\
\hline CYBER $170 / 740$ & CDC-MINN & & NOS -485 & FORTRAN 5 & 60 & $4 / 30 / 80$ \\
\hline CYBER $170 / 750$ & CDC-MINN & $\because$ & - NOS -485 & FORTRAN 5 & 60 & $4 / 30 / 80$ \\
\hline CYBER $170 / 760$ & CDC-MINN & & NOS-485: & FORTRAN 5 & 60 & $4 / 30 / 80$ \\
\hline CYBER 203 & CDC-MINN & $\cdot$ & 0.5 .1 .4 & RI. 4 & 64 & $5 / 22 / 79$ \\
\hline CYBER 175 & United Compating & systems & $\mathrm{APEX} / \mathrm{SL}$ D. 3.4 & FTN 40 & 60 & $11 / 16 / 79$ \\
\hline CRAY -1 & United Computing & Systems & $\cos$ & CFT1.07 & 64 & $6 / 03 / 80$ \\
\hline AMDAHL & Sunnyvale, $C A$ & & MVS 3.8 & Level $\mathrm{H}--$ Extended & 32 & $8 / 08 / 80$ \\
\hline
\end{tabular}


MEGAFLOPS

\begin{tabular}{|c|c|c|c|c|c|c|c|c|c|c|c|c|c|c|c|c|c|c|c|c|}
\hline \multirow[b]{2}{*}{ Kerne 1 } & \multirow[b]{2}{*}{$\begin{array}{l}C D C \\
6400 \\
\end{array}$} & & \multicolumn{3}{|c|}{$\mathrm{CDC}$} & \multicolumn{3}{|c|}{ CYBER } & \multicolumn{3}{|c|}{ CYBER } & \multicolumn{3}{|r|}{ CYBER } & \multirow[b]{2}{*}{$\begin{array}{c}\text { AMDAHL } \\
\text { 78 } \\
\end{array}$} & \multirow[b]{2}{*}{$\begin{array}{l}\mathrm{CDC} \\
7600 \\
\end{array}$} & \multirow[b]{2}{*}{$\begin{array}{l}C D C \\
203 \\
\end{array}$} & \multirow{2}{*}{$\begin{array}{c}\text { UCS } \\
\text { CRAY } \\
\text { CFI }=1.07\end{array}$} \\
\hline & & $\begin{array}{l}\text { CDC } \\
\underline{172} \\
\end{array}$ & $\begin{array}{r}170 / \\
720 \\
\end{array}$ & $\begin{array}{l}\mathrm{FAX} \\
\mathbf{3 8 0} \\
\end{array}$ & $\begin{array}{l}\text { UNIVAC } \\
1108 \\
\end{array}$ & $\begin{array}{r}170 / \\
730 \\
\end{array}$ & $\begin{array}{l}\text { UNIVAC } \\
1100 / 82 \\
\end{array}$ & $\begin{array}{l}C D C \\
6602\end{array}$ & $\begin{array}{r}170 / \\
740 \\
\end{array}$ & $\begin{array}{l}\text { AMDAHL } \\
\text { V7B }\end{array}$ & $\begin{array}{l}\text { IBM } \\
3033 \\
\end{array}$ & $\begin{array}{r}170 / \\
750 \\
\end{array}$ & $\begin{array}{l}\text { AMDAHL } \\
\text { ViA } \\
\end{array}$ & $\begin{array}{l}\text { CDC } \\
175 \\
\end{array}$ & $\begin{array}{c}\text { A'DAHL } \\
\text { V7 } \\
\end{array}$ & $\begin{array}{r}170 / \\
760 \\
\end{array}$ & & & & \\
\hline 1 & .12 & .15 & .19 & .17 & .27 & .27 & .56 & .63 & .73 & 1.6 & 1.4 & 2.0 & 2.0 & 2.0 & 2.6 & 2.7 & 2.8 & 3.6 & 3.9 & 6.3 \\
\hline 2 & .15 & .22 & .24 & .26 & .23 & .35 & .47 & .55 & .99 & 1.7. & 1.7 & 2.5 & 1.9 & 2.4 & 2.3 & 2.8 & 2.6 & $2: 9$ & 5.9 & 11.2 \\
\hline 3 & .12 & .16 & .18 & .25 & .27 & .26 & .51 & .60 & .75 & 1.6 & 1.8 & 1.8 & 1.8 & 2.2 & 2.3 & 2.4 & 2.6 & 3.3 & 5.7 & 19.4 \\
\hline 4 & .13 & .16 & .19 & .30 & .22 & .25 & .47 & .57. & .65 & 1.8 & 2.0 & 1.5 & 2.2 & 1.5 & 2.5 & 2.2 & 2.9 & 3.1 & 5.3 & 5.4 \\
\hline 5 & .15 & .16 & .20 & .24 & .23 & .28 &.$<3$ & $-\leqslant 2$ & .67 & i. 4 & 1.4 & 1.5 & 1.8 & 1.8 & $2 . J$ & .2 .2 & 2.2 & 3.0 & 4.2 & 3.7 \\
\hline Tota 1 & .13 & .17 & .20 & .24 & .24 & .28 & .58 &. .77 & $: 74$ & $1.6^{\circ}$ & 1.6 & 1. 8 & 1.9 & 1.9 & 2.3 & 2.4 & 2.6 & 3.2 & 4.9 & 6.6 \\
\hline
\end{tabular}


Distribution:

Deway ne Rodman, M.C. 45

Bendix Corporation

95 and Troost

Kansas City, MO 64141

Bijoy Chatterjee

Engineering Manager

TRW Array Processors

1140 Mountain View-Alviso Road

Sunnyvale, CA 94086

Jackie Kessler

Building 2824

P.O. Box 8048

General Electric Co.

Philadelphia, PA 19101

Bob Bruce

Amdahl Corporation

5454 Wisconsin Avenue

Washington, DC. 20015

Ray Anastos

UNI VAC

2201 San Pedro Drive

Albuquerque, NM

Steve Zenos

I BM

2444 Louisiana Blvd. NE

Albuquerque, NM 87110

Terry Atkinson

United Computing Services

9034 East Easter Place

Suite 100

Englewood, co 80112

Burton Colvin

National Bureau of Standards

washington, DC 20234

Ray Doty

Control Data Corporation

300 San Mateo, NE

Albuquerque, NM 87108

Andy Reddish

Digital Equipment Corporation

5700 Kircher, NE

P.O. Box 499

Albuquerque, NM 87103
Phyllis Fox

Bell Telephone Laboratories

Murray Hill, NJ 07974

C. B. Moler

Dept. of Computer Science

Univ. of New Mexico

Albuquerque, NM 87110

R. W. Hippe

Cray Research

6400 Uptown Blvd.

Suite $361 \mathrm{~W}$

Albuquerque, NM 87110

Kirby Fong

L-560

P.O. Box 5509

Livermore, CA 94550

Al Erisman

Boeing Computer Services

Energy Technology Applications

Division

Org. G-4500, Mail stop 9C-01

565 Andover Park West

Tukwila, WA 98188

H. L. Shapiro

Dept. of Computer Science

Univ. of New Mexico

Albuquerque, NM 87110

Col. Leonard Stans, AFWL/AD

David E. McIntyre, AFWL/AD.

Bill Buzbee, LANSL

Ann Hays, LANSL

Jack Wor Iton, LANSL

Bob Ewald, LANSL

1100 C. D. Broyles

1522 G. L. West

2000 E. D. Reed

2110 C. W. Gwyn

2100 C. F. Bilo

2424 G. Carli

2600 L. E. Hollingsworth

2610 D. C. Jones

2614 A. R. I acoletti

2614 R. E. Jones

2620 R. J. Detry

2630 E. K. Montoya

2635

P. A. Lemke 


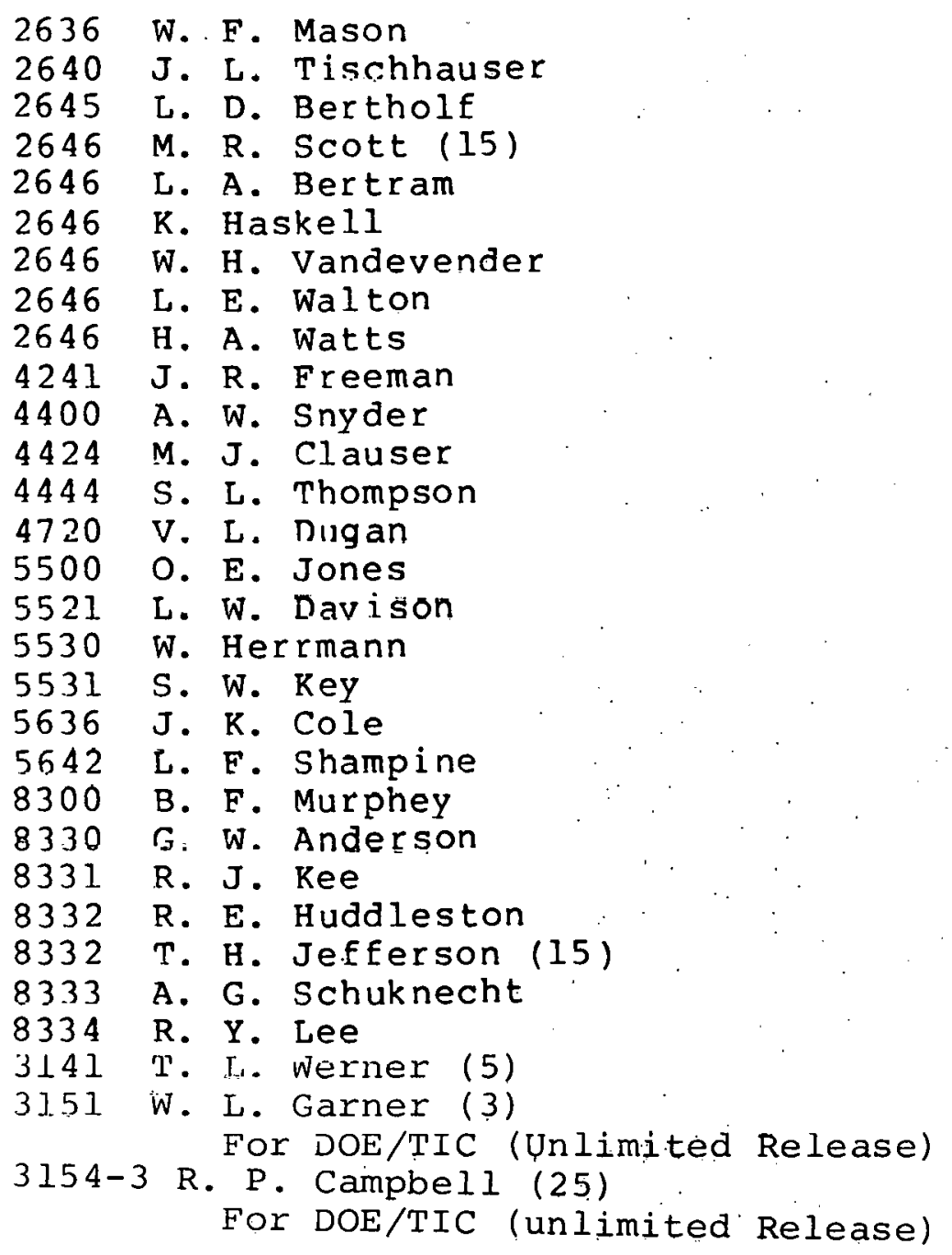


UNCLASSIFIED

No.

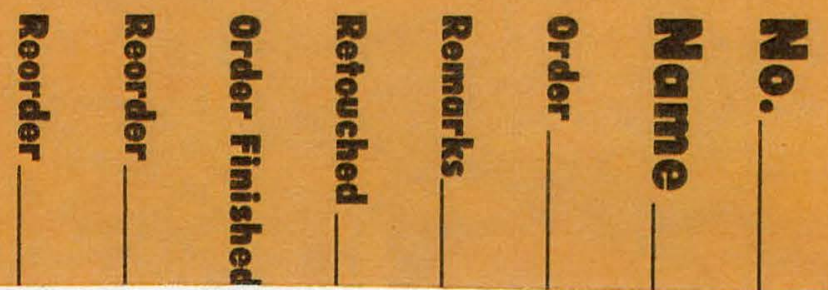

TITLE

ORG.

DATE 


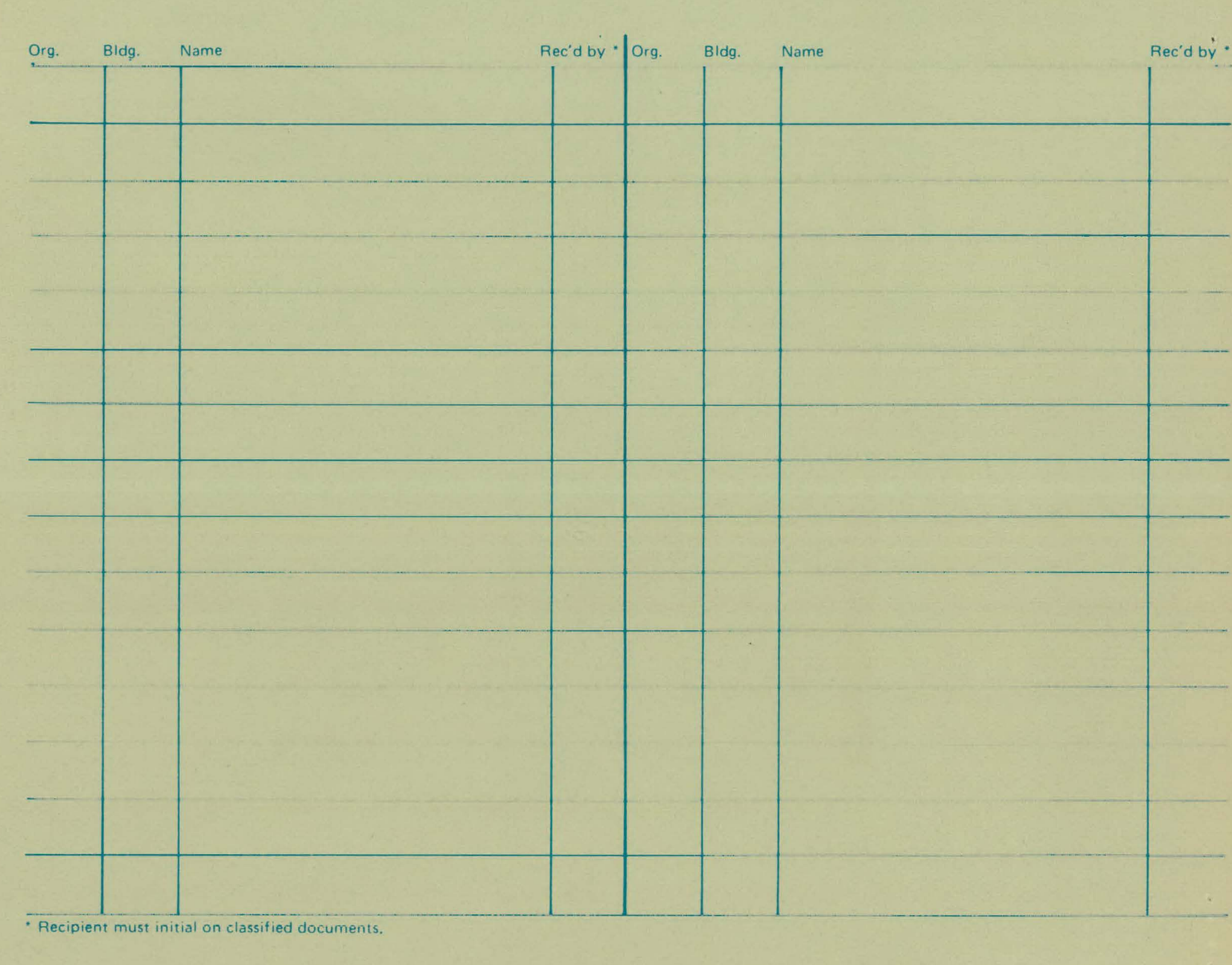

